\title{
The Guest Speaker Management Process
}

\author{
Barry A. Friedman
}

Barry A. Friedman (barry.friedman@oswego.edu) is Professor of Organizational Behavior and Human Resource Management at the State University New York at Oswego

\begin{abstract}
Guest speakers are used widely across disciplines and make valuable contributions to academic courses, organizational training programs, and conferences. Unfortunately, the benefits of using guest speakers are often not realized and little guidance exists regarding how faculty should effectively manage them. This paper details a guest speaker management process to increase guest speaker effectiveness. The objective is for guest speakers to make more relevant and compelling contributions to student larning. Implications for faculty that use guest speakers in their curriculum are provided.
\end{abstract}

Keywords: guest speaker, pedagogy

DOI: https://dx.doi.org/10.15239/j.brcadvje.2020.04.04.ja05 


\section{INTRODUCTION}

Instructors use a wide variety of teaching methods to effectively engage students and accommodate their various learning styles (Kamboj \& Singh, 2015; Roehl, 2013). These methods include role plays, case studies, white boards, cooperative learning, field trips, and computer simulations. Guest speakers are also potentially valuable contributors to academic courses, organizational training programs and conferences as they contribute real world experiences, increase subject matter relevance, and reinforce otherwise abstract concepts presented in the classroom. Students generally find some guest speakers engaging and at the least, decreases boredom associated with being exposed to only the instructor (Hew et al, 2018). Secondary guest speaker advantages include increased student networking with guest speakers that may result in organizational internships and subsequent job opportunities. Finally, guest speakers increase students' ties with the community that reinforces most university missions for greater student community involvement.

Despite the advantages of using guest speakers, the benefits of using them are often not realized. Lack of availability and last minute scheduling changes by organizations' leaders are among the challenges of working with guest speakers (Sortedahl \& Imhoff, 2016). Instructors are often disappointed when guest speakers stray from course learning objectives, entertain students with "war stories" of little pedagogical value, or don't provide effective role models. Of greater concern is the presentation of inappropriate, unethical or examples that demonstrate a conflict of interest. Persaud (2014) described just such a case where a guest speaker from an opioid manufacturer presented a pain management lecture to pharmacy students that advocated wide opioid use, but did not disclose his affiliation with the opioid manufacturer- a clear conflict of interest between the speaker's organizational goals and university values.

This paper details a guest speaker management process to increase guest speaker effectiveness. The objective is for guest speakers to make more relevant and compelling contributions to student learning. Implications 
for faculty that use guest speakers in their curriculum are provided. We begin with a literature review, followed by a proposed speaker management process, and conclude with implications for faculty that wish to use guest speakers in their curriculum.

\section{LITERATURE REVIE W}

Guest speakers are widely used in higher education (Sortedahl \& Imhoff, 2016; Chesnut and Tran-Johnson, 2013; Smith, Pettinga \& Bowman, 2012). Additionally, guest speakers are widely used across academic disciplines and cultures (Jones, Jones, Skinner and Packham, 2013; Kubal, Meyler, Stone and Mauney, 2003; Murray and Bollinger, 2001). Guest speakers are also deployed in primary and secondary education (Kim and Vail, 2011), industry (Armatas and Papadopoulos, 2013) and self-development courses (Bass, Drake, and Linney, 2007). Despite the prevalence of their use in academic and non-academic courses, training and conferences, the literature offers little guidance regarding the effective selection, motivation and management of guest speakers.

In order to address availability and scheduling challenges associated with inviting competent and highly sought after guest speakers, several studies have investigated alternative delivery methodologies including videotaped guest speakers (Sortedahl \& Imhoff, 2016; Roehl, 2013). Kim and Vail, 2011), telephone (Ballard, 2008), podcasts (Strickland, Gray and Hill, 2012) and synchronous computer-mediated communication (Chou, 2001).

While these delivery methods mitigate availability issues, the central issue of selecting and managing guest speakers to better align speakers with learning objectives and maximize learning outcomes has not been adequately addressed. Cox (2017) provided general guidance for primary school teachers, including general advice regarding selecting and hosting guest speakers (e.g., confirm date, facility parking, and offer a thank you gift). Zorek, Katz and Popovich (2011) found that guest speakers enhanced 
pharmacy students' knowledge of career paths, and offered an excellent guest speaker evaluation survey that measured such useful items (e.g., "the guest speaker exposed me to pharmacy career opportunities I did not know about beforehand" and "helped me begin to formulate my career goals"). While helpful in evaluating guest speakers after the fact, this paper offers a more comprehensive process of managing guest speakers before, during and after their involvement. For the purposes of this paper, guest speakers in higher education are emphasized.

\section{Guest Speaker Management}

A comprehensive guest speaker management process (henceforth referred to as "management process") addresses actions taken before, during and after the guest speaker is directly involved in the course. Figure 1 contains a depiction of the management process.

\section{Figure 1. The Guest Speaker Management Process}

\section{Establish Learning Objectives}

The management process begins with setting "S.M.A.R.T." This acronym stands for learning objectives that are: specific, measureable, achievable, realistic and timely. The S.M.A.R.T. goal concept across many contexts (Wood, 2011; Bronson and Stern, 2011), and is especially germane here. Special care should be devoted to determining the learning objectives because they provide guidance for each step of the management process that follow. Congruent with goal setting theory (Latham and Yukl, 1975), well-constructed objectives influence the speaker choice, management, assessment and performance feedback. A student learning objective example might be "the student will be able to state how to address resistance to change in an organizational change initiative. Guest speaker responsibilities might therefore include (1) "provide organizational 
examples of recent change management initiatives, (2) describe how resistance to change occurred, (3) state how the organization addressed the resistance, and finally, (4) state the effectiveness of the change initiative".

\section{Assess Student Learning Needs}

A student needs assessment is appropriate so that valuable time is allotted to what students need to know and not wasted on what students already know. For example, experienced guest speakers can address the gap between students' understanding of theories and their practical application. Many undergraduate students lack significant organizational experience, and lack a context that enhance understanding of otherwise abstract concepts. That is, guest speakers can provide concrete example of abstract concepts. On the other hand, non-traditional students or graduate students with prior organizational experience may not benefit as much as undergraduates from concrete examples of an abstract concept. Of course, speakers with experience in industrial sectors that are different than the experiences of even experienced students can still be valuable.

\section{Establish Speaker Applicant Pool}

As with any staffing situation, creating an applicant pool of competent and diverse potential speakers is an important initial step. Potential speakers can be identified by word of mouth (Cox, 2011), local organizations, an established speaker bureau, other disciplines within the university, or by general reputation. Examples include the American Program Bureau (2017) and Stanford University (2017). Many speakers will contribute to the university on a pro-bono basis, but a budget may be required if a speaker requires a fee. If no speaker budget is available, using established speaker bureaus may not be feasible as they typically charge fees. Potential speakers that are employed in organizations and are known to alumni or faculty may be acceptable for the guest speaker applicant pool. 


\section{BRC Journal of Advances in Education Vol. 4, No. 1}

\section{Interview and Select Guest Speaker}

Potential applicants can be quickly vetted using references and interviews. Contacting trusted individuals that have observed the potential speaker present to a student audience can be very useful. References might include known faculty or student attendees at past presentations. A short list of potential guest speakers can then be interviewed to further assess their suitability for the specific class and subject matter. The central concern is the applicants' ability to facilitate students' achieving the learning objectives established in step 1.

\section{Preview Complete}

This concludes the free, limited preview of this paper. Please buy full access.

\section{Citation Information}

Friedman, Barry A. "The Guest Speaker Management Process." BRC Journal of Advances in Education 4, no. 1 (2020): 73-86. https:// dx.doi.org/10.15239/j.brcadvje.2020.04.01.ja05 